\title{
DIAGNÓSTICO EM FREUD E LACAN: OBJETIVOS, MÉTODOS E CRITÉRIOS
}

\author{
Marcos Chedid Abel ${ }^{1}$
}

[Enviado a 27-03-2011. Aceite a 18-06-2012]

Resumo: Investigam-se as concepções de diagnóstico em Freud e Lacan, quanto a objetivos, métodos e critérios. Chega-se à conclusão de que interessa a esses autores o diagnóstico estrutural, ou seja, a posição subjetiva do candidato a tratamento. Ressalta-se a importância de o diagnóstico ser tomado apenas como hipótese inicial e sujeita a modificação durante o tratamento.

Palavras-chave: Diagnóstico; Método; Freud; Lacan.

Diagnostic in Freud and Lacan: Objectives, Methods and Criteria (Abstract): The conceptions of diagnostic in Freud and Lacan are investigated, considering their objectives, methods and criteria. In the conclusion is considered that the authors have a structural diagnostic view, that is, the subjective position of the candidate to treatment. The importance of the diagnostic is highlighted as an initial hypothesis, susceptible of modifications during the treatment

Keywords: Diagnostic; Method; Freud; Lacan.

Do ponto de vista psiquiátrico, sou um hístero-neurastênico...

Fernando Pessoa (1919/1998, p. 58.)

Sabes quem sou? Eu não sei. Fernando Pessoa (1934/1969, p. 571)

${ }^{1}$ Doutor em psicologia, mestre em psicologia clínica, psicólogo. Coordenador e Docente no Curso de Especialização em Teoria Psicanalítica do Centro Universitário de Brasília (UniCEUB), Brasil.

Endereço: SQN 402, Bloco G, AP. 110. Brasília, DF, Brasil. 70834-070.

Telefone: (+5561) 812698 86. E-mail: mcabel@ig.com.br 
Apresento aqui o resultado de uma pesquisa a respeito do diagnóstico na prática psicanalítica segundo as perspectivas de Sigmund Freud (1856-1939) e Jacques Lacan (1901-1981), em que tive como meta investigar suas concepções dos objetivos e modos do diagnóstico em suas práticas, tendo como fio condutor a indagação quanto às semelhanças e diferenças do diagnóstico nesses autores. O método utilizado foi de pesquisa bibliográfica fundamentada em textos desses autores, como também de seus comentadores.

$\mathrm{O}$ interesse pelo tema teve origem nas discussões, que continuam em curso, quanto aos objetivos, métodos e critérios diagnósticos no âmbito do tratamento psíquico e as freqüentes divergências na definição do diagnóstico que se verificam entre os profissionais. Constata-se que o estabelecimento do objetivo (prognóstico) a ser alcançado pela intervenção (técnica) é condicionado pelo diagnóstico (método) e seus critérios (sinais e sintomas), fundamentados em uma teoria a respeito do que é o ser humano, que tem como pano de fundo uma visão de mundo compartilhada em extensão variável, visto a diversidade de perspectivas encontradas atualmente.

O diagnóstico se caracteriza como método (do grego meta, na direção de, e odos, caminho) (Julia, 1964/1969, p. 203), pois implica em investigação com vista à produção de conhecimento. "Conjunto de procedimentos e regras para chegar ao resultado desejado (geralmente: o conhecimento verdadeiro)" (Russ, 1991/1994, p. 185). Assim, "interrogar-se sobre o 'método' é interrogar-se sobre o 'caminho' seguido em uma investigação" (Julia, 1964/1969, p. 203).

Já as intervenções estão no âmbito da técnica ("do grego tekhnikos, que diz respeito a uma arte, de tekne, arte manual, indústria, habilidade para fazer algo"), definida como "aplicação prática do conhecimento científico teórico" (Japiassu \& Marcondes, 1990, p. 232), "procedimentos pelos quais se aplicam conhecimentos científicos para obter determinado resultado" (Russ, 1991/1994, p. 286).

Etimologicamente, o termo diagnóstico tem origem no adjetivo grego diagnóstikós, que significa "capaz de distinguir, de discernir" (Antônio Houaiss, 2001, verbete diagnóstico). Substantivo na locução grega hé diagnóstikê tékhné "arte de distinguir (doenças)" (Oxford Advanced Learner's Compass, 2005, verbete diagnostic, tradução nossa). Sinônimo de diagnose, do grego diágnósis "discernimento, ação e faculdade de discernir" (Instituto Antônio Houaiss, 2001, verbete diagnose). Derivado do verbo grego diagignôskó "distinguir", formado de diá- "através" e gignôskó "conhecer" (Dicionário Etimológico, verbete diagnóstico).

$\mathrm{Na}$ medicina, diagnóstico indica "conhecimento ou determinação duma doença pelo(s) sintoma(s), sinal ou sinais e/ou mediante exames diversos (radiológicos, laboratoriais, etc.)" como também "o conjunto dos 
dados em que se baseia essa determinação" (Ferreira, 1999, verbete diagnóstico). Diagnóstico implica em descrição, definição da etiologia e classificação. Como coloca Dor (1991), na medicina, o diagnóstico se processa baseado em uma semiologia, com o objetivo de observação para determinar a natureza da doença (etiologia), como também de classificação para enquadre em uma nosografia (diagnóstico diferencial). Além disso, é a base para o estabelecimento do prognóstico e do tratamento, ou seja, é a etapa inicial de um tratamento, visto ser necessário que se defina o diagnóstico antes da implementação dos procedimentos terapêuticos (pp. 13-14).

No campo da saúde mental, na década de 60, o diagnóstico teve sua abolição proposta pelos antipsiquiatras, que abdicavam de qualquer saber prévio a respeito do sujeito e para quem a loucura seria uma experiência existencial a ser vivenciada e testemunhada, com o louco, em seu voo, podendo, talvez, um dia chegar a pousar (Laing, 1967/1974; Cooper, 1967/s.d.).

Em 2006, nos Estados Unidos da América, a Alliance of Psychoanalytic Organizations, publicou o Psychodynamic diagnostic manual $(P D M)$, por considerar precária a perspectiva do diagnóstico baseada somente em sintomas, tal como promulgada pelo DSM, da American Psychiatric Association (2003) e o CID, da Organização Mundial de Saúde (1993). Nesse manual busca reafirmar o valor da psicanálise para o diagnóstico do sofrimento psíquico, com a proposta de que o diagnóstico deve ser baseado antes na personalidade que nos sintomas.

$\mathrm{O}$ trabalho está estruturado em duas partes. $\mathrm{Na}$ primeira, abordo o diagnóstico em Freud. Inicialmente, no que diz respeito a seus objetivos, métodos e critérios, tanto no tratamento catártico, como no psicanalítico. Posteriormente, tomo em consideração a questão do sintoma típico e do sintoma individual no tratamento. Na segunda parte, trabalho o diagnóstico em Lacan. Primeiramente, no que concerne a seus objetivos, métodos e critérios. Em seguida, abordo a análise do particular. Por fim teço algumas conclusões.

\section{O Diagnóstico em Freud}

\section{Objetivos, métodos e critérios do diagnóstico em Freud}

A importância do diagnóstico em Freud é patente na bem-humorada história de um médico da sua cidade natal, que diagnosticava sempre os pacientes como enfeitiçados. Diagnóstico que era recebido por todos, para surpresa de Freud, com contentamento (Freud, 1933/1997, Conf. 34).

Constata-se que o objetivo principal de Freud quanto ao diagnóstico é distinguir, com objetivo de selecionar para empreender uma psicanálise, casos que, em sua opinião, poderiam ser beneficiados por esse método de 
tratamento. Seleção que implica critérios referentes ao quadro clínico, mas também ao caráter do candidato ao tratamento.

Preocupação que já está presente desde o tempo do método catártico, quando este era considerado procedimento terapêutico específico para histeria. Entretanto, são patentes as dificuldades encontradas por Freud quanto ao diagnóstico, já presentes nos Estudos sobre a histeria (1893-1895/1997), onde coloca que para a indicação do tratamento catártico, era preciso que fossem estabelecidos critérios diagnósticos, isto é, a definição das características que diferenciariam a histeria das outras neuroses. Características que não se resumiriam aos sintomas, mesmo que os levando em consideração, mas também à etiologia destes. Ou seja, diagnóstico não apenas baseado nos sintomas (diagnóstico sintomático), mas principalmente na etiologia (diagnóstico etiológico). No entanto, nessa tarefa constata que:

É muito difícil obter uma visão clara de um caso de neurose antes de tê-lo submetido a uma análise minuciosa - uma análise que, na verdade, só pode ser efetuada pelo uso do método de Breuer; mas a decisão sobre o diagnóstico e a forma de terapia a ser adotada tem de ser tomada antes de se chegar a qualquer conhecimento assim minucioso do caso. (Breuer \& Freud, 1893-1895/1997, Cap. 4, Parte 1).

Situação que permanecerá no método psicanalítico, tal como no método catártico, em que o método de diagnóstico é também o método de tratamento, pois ambos se caracterizam pela investigação da etiologia, ou seja, pela busca do conhecimento das determinantes dos sintomas. Diferentemente do que em geral ocorre no campo médico, onde diagnóstico e procedimento terapêutico se dão em momentos distintos, sendo que a definição do diagnóstico (método) precede e indica a intervenção mais adequada (técnica).

Investigação, pesquisa da origem dos sintomas, que no método catártico se dava pelo uso da sugestão hipnótica, no método da pressão pela sugestão e no método psicanalítico pela adoção da regra fundamental da associação livre (freie Assoziation). Com a etiologia sendo pensada por Freud desde os "Estudos", como defesa (Abwer) psíquica, a partir da concepção de representações antitéticas (Kontrastvorstellung) (Breuer \& Freud, 1895/1999, p. 148), até a concepção de resistência (Widerstand), cuja importância, a partir do caso de Elisabeth, é evidenciada pelo método da pressão (Breuer \& Freud, 1893-1895/1997, Caso 5). Resistência à reprodução de lembranças, que Freud vai considerar estando também na origem da amnésia histérica, como defesa:

Uma nova compreensão pareceu abrir-se ante meus olhos quando me ocorreu que esta sem dúvida deveria ser a mesma força psíquica que desempenhara um papel na geração do sintoma histérico e que, na época, impedira que a representação patogênica se tornasse consciente. (Breuer \& Freud, 1893$-1895 / 1997$, Cap. 4, Parte 2). 
Defesa psíquica que vai se constituir como base da teoria etiológica de Freud, que, em suas três modalidades, recalque (Verdrängung), denegação (Verneinung) e recusa (Verleugnung), está no fundamento das neuroses, perversões e psicoses, em conexão com a experiência individual - mesmo que sempre supondo poder estar participando também a constituição. Concepção de defesa cujo primeiro aparecimento em texto publicado ocorre em "As neuropsicoses de defesa" (1894/1997), onde esta é proposta na etiologia das conversões e fobias (o que nomeia então como histeria de defesa), das representações obsessivas e da confusão alucinatória (psicose).

Quanto à técnica, enquanto no tratamento catártico, sob hipnose, predominava a comunicação ao paciente ou a sugestão para o esquecimento das reminiscências que emergiam, com vista a modificações no funcionamento psíquico, no psicanalítico vai prevalecer a arte da interpretação e da construção.

Frente às dificuldades na definição de um diagnóstico prévio ao tratamento, para selecionar os casos de histeria, que poderiam ser tratados pelo método catártico, Freud adota o diagnóstico provisório, que se baseava nos sintomas típicos da histeria. Entretanto, veio a aplicar o tratamento também a outros quadros, como os obsessivos, obtendo resultados terapêuticos e ampliando com isso o âmbito do método (Breuer \& Freud, 1893$-1895 / 1997$, Cap. 4, Parte 1).

Já no método psicanalítico, é adotado o tratamento provisório ou experimental, por uma ou duas semanas, constituindo-se como "uma 'sondagem', a fim de conhecer o caso e decidir se ele é apropriado para a psicanálise." (Freud, 1913/1997). Quando busca distinguir se é um caso de neurose ou psicose.

Ou seja, enquanto no método catártico, a princípio, o objetivo primordial do diagnóstico era selecionar os casos de histeria, no método psicanalítico é diferenciar as neuroses das psicoses, com objetivo de poupar tempo e dinheiro do paciente, como também preservar o crédito do método psicanalítico, não recebendo casos que seriam intratáveis (Freud, 1913/1997). Excluindo, além das psicoses, o que nomeia como "condições narcísicas", como nessa passagem:

Já sabem os senhores que o campo de aplicação da terapia analítica se situa nas neuroses de transferência - fobias, histeria, neurose obsessiva - e, além disso, anormalidades de caráter que se desenvolveram em lugar dessas doenças. Tudo o que difere destas, as condições narcísicas e psicóticas, é inevitável [inadequado] ${ }^{2}$ em grau maior ou menor. Seria inteiramente legítimo acautelar-nos dos insucessos, excluindo cuidadosamente esses casos. Tal precaução levaria a uma grande melhora nas estatísticas da análise. Todavia,

2 Ungeeignet (Freud, 1933/1999, p. 167). 
aqui há uma armadilha. Nossos diagnósticos são feitos após os eventos... Não podemos julgar o paciente que vem para tratamento (ou, igualmente, o candidato que vem para formação), senão depois de havê-lo estudado analiticamente por algumas semanas ou meses. De fato, estamos comprando nabos em saco. O paciente traz consigo aspectos doentios indefinidos e gerais que não comportam um diagnóstico conclusivo. (Freud, 1933/1997, Conf. 34).

Entretanto, além dessa indicação do tratamento para as neuroses (como também em Freud, 1926/1997), em vários momentos de seu trabalho afirma não descartar a possibilidade de se alcançar resultados também com psicoses, em decorrência da ampliação do conhecimento (Freud, 1924/1997, Parte 4) e de modificações no método psicanalítico (Freud, 1905/1997). Possibilidade que também se apresenta nas aproximações que faz entre o sonho e a psicose, concebendo o sonho como uma psicose breve, útil, e que cede à função normal (Freud, 1940/1997, Capítulo 4; Freud, 1900/1997, Cap. 7, Parte C).

Porém, predomina no texto freudiano a presença das dificuldades para o tratamento das psicoses, no que diz respeito à transferência (tal como em Freud, 1933/1997, Conf. 34).

Quanto aos critérios diagnósticos, podemos verificar em seus relatos clínicos que, para a elaboração da hipótese diagnóstica estrutural, Freud se baseia principalmente nos sintomas típicos, mas também no modo do sujeito se posicionar frente ao sintoma. Como fica bastante explícito no caso de Elisabeth em sua belle indifférence em relação aos seus sofrimentos e a manifestação de afeto incongruente com o sintoma nos músculos das pernas (Breuer \& Freud, 1893-1895/1997, Caso 5).

No entanto, além da estrutura psíquica, outros critérios também são considerados para a aceitação de um candidato a tratamento. No método catártico, distinguir a presença de fatores orgânicos em causa, além de outras capacidades no paciente, tais como inteligência e confiança (Breuer \& Freud, 1893-1895/1997, Cap. 4, Parte 1).

Também participam na seleção considerações de ordem pessoal por parte do terapeuta, na forma de aprovação e interesse pelo paciente, pois como diz Freud:

Não consigo me imaginar sondando o mecanismo psíquico de uma histeria de alguém que me causasse a impressão de ser vulgar e repelente e que, num conhecimento mais íntimo, não fosse capaz de despertar solidariedade humana. (Breuer \& Freud, 1893-1895/1997, Cap. 4, Parte 1).

No método psicanalítico, Freud relaciona outros critérios referentes às qualidades exigidas ao candidato a paciente. Além da caracterização do quadro como neurose, é preciso verificar se possui boa formação e caráter, se buscou tratamento pelo seu sofrimento e não em obediência a alguém, 
idade até cerca de 50 anos e que não haja urgência quanto a risco de vida, tal como na anorexia histérica. Esboçando a possibilidade do tratamento de psicoses por meio de alterações no método (Freud, 1905/1997). Critérios de seleção que haviam sido colocados de forma mais concisa um ano antes (Freud, 1904/1997).

\section{Diagnóstico e tratamento: sintoma típico e sintoma individual}

Freud expõe que a psicanálise leva em conta a forma do sintoma, mas valoriza principalmente o conteúdo deste, supondo que o conteúdo diz respeito à experiência do sujeito, isto é, que o sintoma tem sentido (Freud, 1916-17/1997, Conf. 17). Pressuposto que define o propósito de uma psicanálise como desvendar o sentido do sintoma (Freud, 1916-17/1997, Conf. 18), que engloba suas origens e seus objetivos:

Temos incluído duas coisas como 'sentido' de um sintoma: o seu 'de onde' e seu 'para quê' ou sua 'finalidade' - ou seja, as impressões e experiências das quais surgiu e as intenções a que serve. Assim, o 'de onde' de um sintoma se reduz a impressões que vieram do exterior, que uma vez foram necessariamente conscientes e podem, a partir daí, ter-se tornado inconscientes através do esquecimento. $\mathrm{O}$ 'para quê' de um sintoma, seu propósito, no entanto, é invariavelmente um processo endopsíquico, que possivelmente teria sido consciente, no início, mas pode igualmente não ter sido jamais consciente e ter permanecido no inconsciente desde o início. (Freud, 1916-17/1997, Conf. 18).

Entretanto nos defrontamos com sintomas típicos e sintomas individuais. Os individuais são os que mais possibilitam conexões com a experiência. Pois os típicos são "quase os mesmos em todos os casos, as distinções individuais neles desaparecem, ou pelo menos diminuem, de tal forma, que é difícil pô-los em conexão com a experiência individual dos pacientes e relacioná-los a situações particulares que vivenciaram". Por outro lado, "quanto mais individual for a forma dos sintomas, mais motivos teremos para esperar que seremos capazes de estabelecer esta conexão". Conexão que será estabelecida pela "interpretação histórica dos sintomas". (Freud, 1916-17/1997, Conf. 17).

No entanto, mesmo nos sintomas típicos, está presente a experiência individual, como, por exemplo, no caso das fobias da histeria de angústia:

Com um background semelhante, diferentes pacientes, não obstante, exibem suas exigências individuais - manhas, como se costuma dizer - que, em alguns casos, se contradizem abertamente umas às outras. Um paciente evita apenas ruas estreitas, e um outro, somente ruas largas; um consegue sair 
somente se houver poucas pessoas na rua, ao passo que um outro apenas sai se existem muitas. (Freud, 1916-17/1997, Conf. 17).

Portanto, a hipótese diagnóstica é baseada nos sintomas típicos, mas o tratamento psicanalítico se apóia principalmente nos sintomas individuais e no que pode haver de individual nos sintomas típicos. Seguindo essa linha de raciocínio, penso que podemos chegar à conclusão de que para Freud tem mais importância no tratamento o sintoma individual que o típico. Ou seja, a hipótese diagnóstica não tem importância decisiva para o curso do tratamento, visto que se pode intervir principalmente nos sintomas individuais e no que há de individual no típico, na busca de seus sentidos conectados às experiências do sujeito.

É a presença da antinomia entre o universal (nomotético) e o particular (ideográfico). A classificação nosográfica que busca abranger todos os casos e o tratamento de cada caso em sua singularidade. Sendo que na psicanálise mais importância tem o particular. $\mathrm{O}$ diagnóstico fica tendo por principal função distinguir os casos que mais se adequariam a essa modalidade de tratamento, seja pelo quadro como também pelas características da pessoa, a princípio como hipótese, sem nenhuma garantia prévia da sua validade.

Mesmo a distinção das neuroses - histeria, histeria de angústia e obsessiva - não seria de grande ajuda na prática, pois remete ao geral, quando, no tratamento, acessível é o individual, aquilo que possibilita a interpretação histórica, fazendo conexões do sintoma com a vida do sujeito. O que é universal escaparia à possibilidade de análise, e, por isso, de resolução. $\mathrm{Ou}$ seja, a estrutura, o modo típico de funcionamento, permaneceria.

A questão que fica em aberto para Freud é a da origem dos sintomas típicos, mais numerosos que os individuais. Que ele propõe estar em conexão com a experiência do que é comum aos seres humanos, como também a possibilidade de ser decorrente da alteração do psiquismo devida ao quadro. Algo que, em sua opinião, estaria para além do alcance da análise, ao menos no momento em que escreve esse texto, a uma distância de mais de vinte anos dos Estudos sobre a histeria (1893-1895/1997).

\section{Diagnóstico em Lacan}

\section{Objetivos, método e critérios do diagnóstico em Lacan}

O objetivo de Lacan quanto ao diagnóstico diz respeito fundamentalmente, como em Freud, ao julgamento da adequação do candidato ao tratamento, ou seja, ao método psicanalítico. Nesse juízo, entram em causa, da mesma maneira que em Freud, questões referentes ao funcionamento psíquico e ao caráter do candidato. 
É possível, tal como propõe Leite (2000, p. 35), a clínica de Lacan ser distinguida em dois modelos: primeiramente, um modelo estrutural, onde continua presente a nosografia freudiana composta por Neurose, Perversão e Psicose, e, posteriormente, um modelo borromeano em que as estruturas são subordinadas ao modo de enlaçamento dos registros Real, Simbólico e Imaginário, as três dimensões da experiência que comparecem no termo abreviado R.S.I.

Na primeira clínica de Lacan continua presente a importância da diferenciação estrutural a ser feita entre neurose e psicose, relacionadas à função paterna, principalmente para evitar a eclosão de uma psicose ainda não manifesta. Pois constata que "acontece de tomarmos pré-psicóticos em análise, e nós sabemos o que isso dá - isso dá psicóticos" (Lacan, 1955$-1956 / 1981$, p. 285 , tradução nossa). Porém Lacan encoraja a não recuar diante da psicose já manifesta (Lacan, 1977, Questions et réponses), como também a não se intimidar pelo perigo de "delirar com o doente" (Lacan, 1959/1966, p. 574, tradução nossa).

O método adotado para o diagnóstico é o das entrevistas preliminares, quando se busca chegar a uma hipótese quanto à possibilidade da instalação do sujeito suposto saber, ou seja, a posição em que será colocado o analista.

No entanto, mesmo com a adoção das entrevistas preliminares, é importante estar alerta, desde o primeiro momento, para o não desencadeamento de uma psicose. Digo isso a partir de uma experiência que tive no início de meu trabalho clínico, quando recebi para tratamento um jovem, então com cerca de 20 anos, que surtou durante a primeira entrevista. Fato que me surpreendeu e pelo qual me repreendi longamente.

Na primeira clínica lacaniana, estrutural, o critério para a distinção entre neurose, perversão e psicose, continua sendo feita em função dos efeitos produzidos pelas defesas à angústia de castração. Isto é, o sintoma, que, no entanto, tem valor não somente pela forma, mas, como solução de compromisso, revelar a posição do sujeito ao desejo e à angústia (Lacan, 1962-1963/2004, p. 324), que resultam na posição do sujeito ao sintoma. Defesas características a cada estrutura (Lacan, 1938/2001, p. 71) e nomeadas por Freud como recalque (Verdrängung), negação (Verneinung) e rejeição (Verwerfung), sendo esta última ressaltada na psicose e nomeada como forclusion por Lacan (1955-1956/1981, pp. 94-102). Defesas que cristalizam estruturas psíquicas, isto é, modos de ser. A distinção entre neurose e psicose é feita pela presença ou não da função paterna, ou seja, o destino do Nom-du-Père (Lacan, 1957-1958/1998).

Na segunda clínica de Lacan, qualificada de borromeana por alguns de seus comentadores, as estruturas se definem "em relação à posição relativa do Simbólico, do Imaginário e do Real” (Lacan, 1978/1982, p. 3, tradução nossa), entrelaçados em um nó borromeano (Lacan, 1974-1975). A perspec- 
tiva que prevalece é a de que o falante é "consequência da relação entre Imaginário, Simbólico e Real" (Leite, 2000, p. 36). Para Alves (2000), as estruturas "mantém um valor de orientação para o analista", mas perdem "o caráter definitivo de classificação", em razão da "multiplicação de referências identificatórias da atualidade" (p. 2). Na perspectiva de Leite (2000), diferentemente da clínica estrutural, categorial, do sim ou não, na borromeana há continuidade, pois o critério está na amarração do nó, que pode estar mais ou menos adequado, ou mesmo o nó pode não ser borromeano (p. 35). Em suas derradeiras elaborações, Lacan (1975-1976/2005) introduz um quarto nó na amarração das três dimensões R.S.I., que vai nomear como sinthome (pp. 19-20).

No entanto, a questão que é comum e decisiva à primeira e à segunda clínica de Lacan, como também em Freud, é a possibilidade de transferência. Isto é, de que aquele que ocupa o lugar de analista possa ser investido do que Lacan nomeia como sujeito suposto saber.

Para Lacan, o critério inicial para a aceitação em tratamento é uma verdadeira demanda de ser livrado de um sintoma, algo que pulse e possa levar a um esforço de análise. Ou seja, é preciso que haja sofrimento, algo mais que a demanda de "se conhecer", que levava Lacan a conduzir o candidato porta fora de seu gabinete (Lacan, 1975, para. 13). Mas o sintoma não é suficiente para a entrada em análise, pois é preciso que o sujeito, após dirigir a questão ao analista, passe a questionar a si mesmo. Portanto é fundamental a posição do sujeito frente ao sintoma, isto é, que se implique em relação ao próprio sofrimento, para que seja tratável pela psicanálise, ou seja, é condição necessária para uma análise que se constitua o sintoma psicanalítico, tal como propõe Lacan (1962-1963/2004, pp. 324-326).

Essa proposta de Lacan é relacionada por Miller (1982/1989) aos registros R.S.I., em três tempos. Primeiramente, é "o tempo em que o sintoma, como não reconhecido, se identificava com a realidade cotidiana" (p. 12). Isto é, quando o sintoma não é percebido como tal, isto é, não incomoda, não é fonte de sofrimento, por haver identificação, indiferenciação, ao sintoma, que Miller adjetiva então como imaginário. $\mathrm{O}$ segundo tempo diz respeito à quebra da continuidade, momento de estranhamento de si, do unheimliche. Emergência do sintoma como alteridade, gerando espanto e incompreensão, falta de sentido, sintoma como enigma, momento da divisão do sujeito, como coloca Wachsberger (1989, p. 29). Quando o sintoma é qualificado por Miller como real, porquanto ainda não simbolizado. $\mathrm{O}$ terceiro tempo é o momento da demanda de saber do sintoma ao analista, da busca de sentido ao sintoma. Tempo em que o sintoma é qualificado como simbólico.

Entretanto, mesmo no caso do sintoma simbólico, Wachsberger (1989) ressalta a importância de se certificar da possibilidade de constituição 
do sujeito suposto saber, diferenciando a "crença no Outro como depositário de um saber", da "queixa a propósito de uma falha de saber concernente a um distúrbio de aparecimento ou agravamento recente" (p. 28). Situação do "Eu gostaria de me conhecer melhor", quando o sujeito apenas "solicita ao analista uma pontinha de saber que lhe falta para dominar a insuficiência que ele reputa passageira", diferente daquela em que se impõe a questão "Quem eu sou" (p. 28).

Portanto, encontramos o diagnóstico, na clínica lacaniana, sendo realizado pelo método das entrevistas preliminares, tendo por critérios os mecanismos de defesa e as modalidades de nó entre Real, Imaginário e Simbólico, com o objetivo principal de evitar quadros de psicose ainda não eclodida. Também levando em conta, como decisivo para o tratamento, a possibilidade da instalação da transferência ao sujeito suposto saber, verificada pela posição do sujeito frente ao sintoma.

\section{Diagnóstico e tratamento: a análise do particular}

Para além dos tipos de sintoma, está a estrutura. "Que os tipos clínicos são marcados pela estrutura, eis quem pode já se escrever ainda que não sem hesitação" (Lacan, 1973/2001, p. 557, tradução nossa). Mas o diagnóstico estrutural não é suficiente e decisivo para a prática, pois "o que emerge da mesma estrutura, não tem forçosamente o mesmo sentido. É nisso que não há análise que do particular: não é absolutamente de um sentido único que procede uma mesma estrutura" (p. 557, tradução nossa). Assim, "os sujeitos de um tipo são, portanto, sem utilidade para os outros do mesmo tipo" (p. 557, tradução nossa). Ou seja, como diz Freud, há que se tomar cada caso como se fosse o primeiro, colocando em suspensão todo o conhecimento prévio. É a condição que possibilita a escuta do particular. Como exposto acima, o que Freud nomeia como análise do individual (Freud, 1916-17/1997, Conf. 17). Pois, como também ressalta Lacan, em uma psicanálise se busca dispor ao analisante "o sentido de seus sintomas" (Lacan, 1973/2001, p. 556, tradução nossa). Isto é, o sentido dos sintomas daquele sujeito em particular.

$\mathrm{Na}$ epistemologia da psicanálise, não há possibilidade da universalização das interpretações, como também da previsão e, com isso, do controle. Pois além da impossibilidade de aplicação do conhecimento de um analisante a outro, não há condições para a previsão em um mesmo analisante. "Não é porque o sentido de suas interpretações tem efeitos que os analistas estão no verdadeiro, já que mesmo sendo ela justa, seus efeitos são incalculáveis. Ela testemunha nenhum saber, pois a tomando em sua definição clássica, o saber se assegura de uma possível previsão" (Lacan, 1973/2001, p. 558, tradução nossa). A psicanálise é uma ciência do particular, uma "experiência do particular" (Lacan, 1953-1954/1975, p. 29, tradução nossa). 
A questão do particular na análise é retomada por Alves (2000), buscando avançar para o singular. "Particularidade é algo distinto entre uma série de elementos, enquanto a singularidade se define a partir de si" (p. 3). Exemplifica o particular, com alguém que faça uma tatuagem, pois mesmo que inédita, é uma particularidade na série de outros que também fizeram tatuagem. A partir disso, defende a proposta de que na análise deve-se buscar o singular, sendo que "o singular é o intransferível, por vezes inexplicável" (p. 4).

$\mathrm{O}$ analisando se entrega a uma pesquisa para encontrar e suportar seu singular, imiscuído entre algumas particularidades. Sua fala é o discurso da série; suas queixas, o senso comum. Ao longo de sua experiência analítica, elementos se destacam, singulares. A análise caminha para a apreensão dos elementos que não podemos explicar ou justificar. 'Identificação ao sintoma', suportar o mais irredutível de si a aprender a viver com isso, a partir disso. (Alves, 2000, p. 4).

Essa seria a via para não cair em um estéril diagnóstico classificatório, ou seja, "o diagnóstico deve buscar a exceção", pois mesmo o diagnóstico do particular inseriria o "sujeito na série" (Alves, 2000, p. 4).

Em perspectiva diversa, Quinet (1991), ressalta a importância em psicanálise do diagnóstico diferencial no que diz respeito à direção da análise, ou seja, "o diagnóstico só tem sentido se servir para a condução da análise" (p. 23). Condução que se refere à transferência, "dado que o analista será convocado a ocupar na transferência o lugar do Outro do sujeito a quem são dirigidas suas demandas" (p. 28). Entretanto, alerta para o fato de que a posição do analista deve ser a de ignorância, mas "ignorância douta", termo de Nicolau di Cusa (Séc. XV), definido como um saber que conhece seus limites (p. 31).

\section{Conclusões}

Constata-se grande afinidade nas perspectivas de Freud e Lacan quanto ao diagnóstico, seja no diz respeito ao método, como também aos objetivos. Pois em ambos o método se caracteriza por um tempo prévio ao tratamento propriamente dito, para a elaboração de uma hipótese diagnóstica. Além disso, em Freud e Lacan, o objetivo principal do diagnóstico é chegar a uma decisão quanto à possibilidade de análise com o candidato. O diagnóstico diferencial prévio tem também utilidade na condução do tratamento, em termos de prognóstico quanto ao lugar do analista na transferência. Contudo, como constata Freud, só se chegaria a um diagnóstico definitivo ao final da análise. Ou seja, diagnóstico é hipótese a ser verificada, pelo analista buscando manter-se na posição de ignorante douto, como faz referência Quinet 
(1991, p. 31), citado acima, ou seja, daquele que conhece os limites de seu saber.

Com respeito aos critérios para o diagnóstico diferencial, em Freud predomina a consideração pelos sinais e sintomas típicos e a distinção estrutural pelos mecanismos de defesa conjecturados a partir daqueles, mas levando também em conta a posição do sujeito frente ao sintoma. Enquanto em Lacan vai-se tomar em consideração, primeiramente, a posição do sujeito no fantasma em relação ao Outro, incluindo, posteriormente, os modos de enodamento do R.S.I. pelo sinthome.

Também se encontram semelhanças de pontos de vista no que concerne ao sintoma individual em Freud e ao particular em Lacan. Pois ambos ressaltam a importância, no tratamento, de ser colocada em primeiro plano a singularidade do sujeito, em proporção inversa à esterilidade, para o processo analítico, de se ater ao caráter universal da nosografia. Fato que é evidente em Fernando Pessoa, citado em epígrafe, para o qual, apesar do autodiagnóstico de hístero-neurastênico, continua se impondo a questão a respeito de quem é. Pois o diagnóstico nosográfico pode se propor a dizer do modo de ser, como é, mas não dá conta do ser, quem é - tanto mais no caso do gênio. Limite, que pela desconsideração é exemplar o médico Mário Saraiva (1999), no engano da pretenção de reduzir o espírito excepcional de Pessoa à nosografia psiquiátrica.

\section{Referências}

Alliance of Psychoanalytic Organizations (2006). Psychodynamic diagnostic manual (PDM). Chicago, IL: Independent Publishers Group.

Alves, F. R. (2000). Do legado de Lacan: A arte do diagnóstico na segunda clínica. Forbes, J. (Dir.). Acessado de http://www.jorgeforbes.com.br/arq/artedodia gnostico.pdf

American Psychiatric Association (2003). Manual diagnóstico e estatístico de transtornos mentais. DSM-IV-TR. Porto Alegre: Artmed.

Breuer, J. \& Freud, S. (1997). Estudos sobre a histeria. In Salomão, E. (Coord.). Edição eletrônica brasileira das obras psicológicas completas de Sigmund Freud (Vol. 2). [1 CD-ROM. Versão 1.0. Não paginado]. Rio de Janeiro: Imago.(Trabalho original publicado em 1893-1895)

Breuer, J. \& Freud, S. (1999). Studien über Hysterie. In Gesammelte Werke (Vol. 1). Frankfurt am Main Fischer Taschenbuch Verlag.(Trabalho original publicado em 1895)

Cooper, D. (s.d.). Psiquiatria e antipsiquiatria. São Paulo: Perspectiva.(Trabalho original publicado em 1967)

Dicionário Etimológico. Acessado de http://www.dicionarioetimologico.com.br/ searchController.do?hidArtigo=D21D1CBF8C5AE91FE694A4F033B8BB3A 
Dor, J. (1991). Estruturas e clínica psicanalítica. Rio de Janeiro: Timbre-Taurus.

Michaelis (1996). Dicionário eletrônico Michaelis [1 CD-ROM. Versão 4.00. Não paginado]. São Paulo: DTS Software.

Ferreira, A. B. H. (1999). Dicionário Aurélio eletrônico: Século XXI [1 CD-ROM. Versão 3.0. Não paginado]. São Paulo: Nova Fronteira.

Freud, S. (1997). As neuropsicoses de defesa. In Salomão, E. (Coord.). Edição eletrônica brasileira das obras psicológicas completas de Sigmund Freud (Vol. 3). [1 CD-ROM. Versão 1.0. Não paginado. Parágrafos irregulares]. Rio de Janeiro: Imago. (Trabalho original publicado em 1894)

Freud, S. (1997). A interpretação dos sonhos. In Salomão, E. (Coord.). Edição eletrônica brasileira das obras psicológicas completas de Sigmund Freud (Vols. 4 e 5). [1 CD-ROM. Versão 1.0. Não paginado. Parágrafos irregulares]. Rio de Janeiro: Imago.(Trabalho original publicado em 1900)

Freud, S. (1997). O método psicanalítico de Freud. In Salomão, E. (Coord.). Edição eletrônica brasileira das obras psicológicas completas de Sigmund Freud (Vol. 6). [1 CD-ROM. Versão 1.0. Não paginado. Parágrafos irregulares]. Rio de Janeiro: Imago.(Trabalho original publicado em 1904)

Freud, S. (1997). Sobre a psicoterapia. In Salomão, E. (Coord.). Edição eletrônica brasileira das obras psicológicas completas de Sigmund Freud (Vol. 7). [1 CD-ROM. Versão 1.0. Não paginado. Parágrafos irregulares]. Rio de Janeiro: Imago.(Trabalho original publicado em 1905)

Freud, S. (1997). Sobre o início do tratamento: Novas recomendações sobre a técnica da psicanálise I. In Salomão, E. (Coord.). Edição eletrônica brasileira das obras psicológicas completas de Sigmund Freud (Vol. 12). [1 CD-ROM. Versão 1.0. Não paginado. Parágrafos irregulares]. Rio de Janeiro: Imago.(Trabalho original publicado em 1913)

Freud, S. (1997). Conferências introdutórias sobre psicanálise. In Salomão, E. (Coord.). Edição eletrônica brasileira das obras psicológicas completas de Sigmund Freud (Vols. 15 e 16). [1 CD-ROM. Versão 1.0. Não paginado. Parágrafos irregulares]. Rio de Janeiro: Imago.(Trabalho original publicado em 1916-17)

Freud, S. (1997). Uma breve descrição da psicanálise. In Salomão, E. (Coord.). Edição eletrônica brasileira das obras psicológicas completas de Sigmund Freud (Vol. 19). [1 CD-ROM. Versão 1.0. Não paginado. Parágrafos irregulares]. Rio de Janeiro: Imago.(Trabalho original publicado em 1924)

Freud, S. (1997). A questão da análise leiga. In Salomão, E. (Coord.). Edição eletrônica brasileira das obras psicológicas completas de Sigmund Freud (Vol. 20). [1 CD-ROM. Versão 1.0. Não paginado. Parágrafos irregulares]. Rio de Janeiro: Imago.(Trabalho original publicado em 1926)

Freud, S. (1997). Novas conferências introdutórias sobre psicanálise. In Salomão, E. (Coord.). Edição eletrônica brasileira das obras psicológicas completas de Sigmund Freud (Vol. 22). [1 CD-ROM. Versão 1.0. Não paginado. Parágrafos irregulares]. Rio de Janeiro: Imago.(Trabalho original publicado em 1933)

Freud, S. (1999). Neue Folge der Vorlesungen zur Einführung in die Psychoanalyse. In Gesammelte Werke (Vol. 15). Frankfurt am Main Fischer Taschenbuch Verlag.(Trabalho original publicado em 1933) 
Freud, S. (1997). Esboço de psicanálise. In Salomão, E. (Coord.). Edição eletrônica brasileira das obras psicológicas completas de Sigmund Freud (Vol. 23). [1 CD-ROM. Versão 1.0. Não paginado. Parágrafos irregulares]. Rio de Janeiro: Imago.(Trabalho original publicado em 1940)

Instituto Antônio Houaiss. (2001). Dicionário eletrônico Houaiss da língua portuguesa [1 CD-ROM. Versão 1.0. Não paginado]. São Paulo: Objetiva.

Japiassu, H., \& Marcondes, D. (1990). Dicionário básico de filosofia. Rio de Janeiro: Jorge Zahar.

Julia, D. (1969). Dicionário de filosofia. Rio de Janeiro: Larousse do Brasil.(Trabalho original publicado em 1964)

Lacan, J. (2001). Les complexes familiaux dans la formation de l'individu: Essai d'analyse d'une fonction en psychologie. In Autres écrits. Paris: Seuil.(Trabalho original publicado em 1938)

Lacan, J. (1975). Les écrits techniques de Freud. In Le seminaire (Vol. 1). Paris: Seuil.(Trabalho original proferido em 1953-1954)

Lacan, J. (1981). Les psychoses. In Le seminaire (Vol. 3). Paris: Seuil.(Trabalho original proferido em 1955-1956)

Lacan, J. (1998). Les formations de l'inconscient. In Le seminaire (Vol. 5). Paris: Seuil.(Trabalho original proferido em 1957-1958)

Lacan, J. (1966). D'une question préliminaire à tout traitement possible de la psychose. In Ecrits. Paris: Seuil.(Trabalho original publicado em 1959)

Lacan, J. (2001). L'angoisse. In Le seminaire (Vol. 10). Paris: Seuil, 2004.

Lacan, J. (1973). Introcuction à l'édition allemande d'un premier volume des Écrits. In Autres écrits. Paris: Seuil.(Trabalho original proferido em 1962-1963)

Lacan, J. (2009). R.S.I. Gaogoa. Acessado de http://gaogoa.free.fr/SeminaireS.htm. Não paginado. Versão não oficial. (Trabalho proferido em 1974-1975)

Lacan, J. (1975). Conférences et entretiens dans des universités nord-américaines. Scilicet $\mathrm{n}^{\circ} 6 / 7$, pp. 32-41.

Lacan, J. (2005). Le sinthome. In Le seminaire (Vol. 23). Paris: Seuil. (Trabalho proferido em 1975-1976)

Lacan, J. (1977). Ouverture de la section clinique. Ornicar?, 9, pp. 7-14.

Lacan, J. (1984). Conférence chez le Professeur Deniker - Hôpital Sainte-Anne. Bulletin de l'Association freudienne, $\mathrm{n}^{\circ}$ 7, pp. 3-4. (Trabalho original proferido em 1978)

Laing, R. D. (1974). A política da experiência e a ave-do-paraíso. Petrópolis: Vozes.(Trabalho publicado em 1967)

Leite, M. P. de S. (2000). Diagnóstico, psicopatologia e psicanálise de orientação lacaniana. Revista latinoamericana de psicopatologia fundamental, IV, 2, 29-40 .

Miller, J.-A. (1989). C.S.T. In Motta, M. B. (Org.), Clínica lacaniana: casos clínicos do campo freudiano (pp. 9-13). Rio de Janeiro: Jorge Zahar. (Trabalho original publicado em 1982)

Organização Mundial de Saúde (1993). Classificação de transtornos mentais e de comportamento da CID-10. Porto Alegre: Artmed. 
Oxford Advanced Learner's Compass (2005). [1 CD-ROM. $7^{\mathrm{a}}$ ed. Não paginado]. Oxford: Oxford University.

Pessoa, F. (1998). Carta a dois psiquiatras franceses. In Pessoa, F.. Obras em prosa. Volume único. Rio de Janeiro: Nova Aguilar. (Trabalho original escrito em 1919)

Pessoa, F. (1969). Poesias coligidas / Inéditas 1919-1935. In Pessoa, F. Obra poética. Volume único. Rio de Janeiro: Nova Aguilar. (Trabalho original escrito em 1934)

Quinet, A. (1991). As 4+1 condições da análise. Rio de Janeiro: Jorge Zahar.

Russ, J. (1994). Dicionário de filosofia. São Paulo: Scipione.(Trabalho original publicado em 1991)

Saraiva, M. (1999). O caso clínico de Fernando Pessoa. Lisboa: Universitária.

Wachsberger, H. (1989). Função das entrevistas preliminares. In Motta, M. B. (Org.), Clínica lacaniana: Casos clínicos do campo freudiano (pp. 26-31). Rio de Janeiro: Jorge Zahar. 